\title{
Endothelin-1 gene polymorphisms and diabetic kidney disease in patients with type 2 diabetes mellitus
}

\author{
Claudete M. Zanatta', Daisy Crispim², ${ }^{1,}$ Denise A. Sortica' ${ }^{1}$, Lucas P. Klassmann ${ }^{1}$, Jorge L. Gross ${ }^{1,2}$, \\ Fernando Gerchman ${ }^{1,2}$ and Luís H. Canani ${ }^{1,2^{*}}$
}

\begin{abstract}
Background and aims: Diabetic kidney disease (DKD) is the leading cause of end stage renal disease worldwide and is associated with increased cardiovascular mortality. The endothelin system has been implicated in the pathogenesis of arterial hypertension and renal dysfunction. In the present study, the association of DKD with polymorphisms in ET-1 (EDN1) and ETRA (EDNRA) genes was analyzed in patients with type 2 diabetes mellitus (T2DM).
\end{abstract}

Methods: A case-control study was conducted in 548 white T2DM patients. Patients with proteinuria or on dialysis were considered cases and patients with normoalbuminuria were considered controls. Two polymorphisms in the EDN1 gene (rs1800541 and rs57072783) and five in EDNRA gene (rs6842241; rs4835083; rs4639051; rs5333 and rs5343) were genotyped and haplotype analyses were performed.

Results: The presence of rs57072783 T allele (TT/TG vs. GG) or rs $1800541 \mathrm{G}$ allele (GG/GT vs. TT) protected against $\mathrm{DKD}(\mathrm{OR}=0.69,95 \% \mathrm{Cl} 0.48-0.99, \mathrm{P}=0.049$; and $\mathrm{OR}=0.60,95 \% \mathrm{Cl} 0.41-0.88, \mathrm{P}=0.009$, respectively). However in multivariate analyses, only the rs $1800541 \mathrm{G}$ allele remained independently associated with DKD $(P=0.046)$.

Conclusions: The present study shows that ET-1 could be involved in the pathogenesis of DKD in patients with T2DM.

Keywords: Endothelin-1, Diabetic kidney disease, Diabetes mellitus type 2

\section{Background}

Diabetic kidney disease (DKD) is the leading cause of chronic kidney disease in patients starting renal replacement therapy [1] and it is associated with increased cardiovascular mortality [2]. Among patients starting renal replacement therapy, the incidence of DKD doubled over the 1991-2001 period. Fortunately, the number of new cases of end stage renal disease (ESRD) in people with diabetes or high blood pressure declined by about 2 percent in 2011 compared with 2010-the first decrease in more than 30 years-which may mean that people with those diseases are getting better treatments [1]. However,

\footnotetext{
*Correspondence: luiscanani@yahoo.com;

luishenriquecanani@gmail.com

${ }^{1}$ Federal University of Rio Grande do Sul, Porto Alegre, Brazil

Full list of author information is available at the end of the article
}

implementation of these measures remains far below desirable goals [3].

Endothelin-1 (ET-1) is the predominant isoform of the endothelin peptide family. It acts through the receptors type A (ETRA) and B (ETRB) $[4,5]$, leading to cell proliferation and vasoconstriction. Human studies and animal experiments have documented that renal synthesis of ET-1 is increased in chronic kidney disease [6, 7]. Endothelial dysfunction increases ET-1 production, leading to vascular hypertrophy, atherogenesis and, in the kidney, glomerulosclerosis [8-10]. Elevated plasma ET-1 levels have been reported in patients with diabetes mellitus [11-13]. We have previously demonstrated that plasma ET-1 levels increases as the urinary albumin excretion increases [14], and that the human kidney with DKD overexpress ET-1 and ETRA [15]. 
However, it stills not clear whether ET-1 is involved in the pathogenesis of DKD or it is only a secondary modulator that promotes progression after disease onset. In this context, genetic studies could be helpful in distinguish primary disease effects from secondary ones. The aim of this study was to evaluate the association between genetic variants of the ET-1 and ETRA genes (EDN1 and $E D N R A)$ and DKD in patients with type 2 diabetes mellitus (T2DM).

\section{Subjects and methods Subjects}

The sample of this nested case-control study is composed of 548 unrelated white patients with T2DM who were included in a multicenter study that started recruiting patients in 2002 [16]. The original project was designed to assess risk factors for the chronic complications of T2DM, and includes four centers located at general hospitals in the state of Rio Grande do Sul, Brazil: Grupo Hospitalar Nossa Senhora da Conceição, Hospital São Vicente de Paula, Hospital Universitário de Rio Grande, and Hospital de Clínicas de Porto Alegre. Ethnic groups were defined on the basis of self-classification. Only patients who described themselves as white were included. In the state of Rio Grande do Sul, white persons are mainly of European ancestry (mostly Portuguese, Spanish, Italian, and German descent).

Patients underwent a clinical and laboratory evaluation as previously described [14]. Blood pressure (BP) was measured in the sitting position twice, with a 5 -min interval between measurements. Weight and height were used to calculate body mass index $\left(\mathrm{kg} / \mathrm{m}^{2}\right)$. Cases were defined by the presence of macroalbuminuria (proteinuria) or dialysis treatment. Albumin excretion rate (AER) was measured in at least three urine collections. Patients were classified in accordance with previously defined local standards [17] as normoalbuminuric (AER $<20 \mu \mathrm{g} /$ min or $<17 \mathrm{mg} / \mathrm{L}$ on a $24-\mathrm{h}$ timed urine or spot random sterile urine sample respectively) or macroalbuminuric $($ AER $>200 \mu \mathrm{g} / \mathrm{min}$ or $>174 \mathrm{mg} / \mathrm{L}$ or current dialysis). T2DM patients with 5 years or more of disease and normoalbuminuria formed the control group. Et-1 was measured in a subgroup of subjects $(n=111)$ regardless being in the control or case group. Since many factors can affect plasma ET-1 levels, ET-1 was measured after discontinuation of angiotensin-converting enzyme (ACE) inhibitor therapy for at least 2 weeks. For this subgroup, a more stringent exclusion criteria was applied and include: renal impairment (serum creatinine $\geq 1.5 \mathrm{mg}$ / $\mathrm{dL}$ ), any cardiovascular event during the 6 months preceding enrolment (stroke, myocardial infarction, unstable angina, lower limb amputation, bypass surgery, or percutaneous coronary intervention), heart failure (New York
Heart Association class II or worse), liver disease (history of liver disease or elevated liver enzymes), any infectious, inflammatory or malignant process. Mean plasma ET-1 values were analyzed according to different genotypes of the EDN1 and EDNRA polymorphisms.

The information obtained from the study did not influence patient diagnosis or treatment in any way. The research ethics committees of the participating centers approved the study protocol, and all patients provided written informed consent.

\section{Laboratory methods}

Laboratory analyses were performed in serum blood sample collected after a 12-h fast as previously described [14]. Fasting blood glucose was determined by the glucose oxidase method; plasma triglycerides and cholesterol, by enzymatic methods; AER, by immunoturbidimetry (SeraPak immuno microalbuminuria, Bayer, Tarrytown, NY, USA; mean intra- and interassay coefficients of variance of 4.5 and $7.6 \%$, respectively); serum creatinine by Jaffe's reaction; glycated hemoglobin $\left(\mathrm{HbA}_{1 \mathrm{c}}\right)$ by ion-exchange HPLC (Merck-Hitachi L-9100 GhB Analyser, reference range 4.7-6.0 \%). Plasma ET-1 was measured by ELISA as previously described [14].

\section{Genotyping}

Genomic DNA was extracted from blood leukocytes by a salting-out procedure [18]. Evaluation of the polymorphism rs4639051 in intron 3 of the EDNRA gene was done by digesting polymerase chain reaction (PCR) products with the HhaI restriction enzyme (New England Biolabs, Inc., Ipswich, MA, USA). Digestion fragments were resolved on $2 \%$ agarose gels containing ethidium bromide and visualized under ultraviolet illumination. Genotypes of the rs4639051 polymorphism were recorded using the ImageMaster VDS system (GE HealthCare, London, UK). The primer sequences used for this polymorphism are forward $5^{\prime}$-GAC TAT CCC AGA CCA CAC CTT CA-3' and reverse 5'-GCT CAG GGC TGC CAA CTC C-3'.

Genotyping of the $\operatorname{rs} 4835083$ (G/A; intron 1), rs1568136 (T/A; intron 2), rs5333 (C/T; exon 6) and rs5343 (T/C; exon 8) polymorphisms in the EDNRA gene and rs1800541 (-T1370G; promoter region) and rs57072783G/T (Lys198Asn; exon 5) in the EDN1 gene was performed using specific primers and probes (Custom TaqMan Genotyping Assay $40 \times$ - Life Technologies, Foster City, CA, USA). One allele-specific probe was labeled with VIC dye and the other was labeled with FAM dye. The total reaction volume of $5 \mu \mathrm{L}$ included 2 ng of genomic DNA, TaqMan Genotyping Master Mix $1 \times$ (Life Technologies), and Custom TaqMan Genotyping Assay $1 \times$ specific for each polymorphism. Plates were 
then placed in a real-time PCR thermal cycler (7500 Fast Real PCR System; Life Technologies) for $10 \mathrm{~min}$ at $95^{\circ} \mathrm{C}$, followed by $40-50$ cycles at $95{ }^{\circ} \mathrm{C}$ for $15 \mathrm{~s}$ and at $63{ }^{\circ} \mathrm{C}$ for $60 \mathrm{~s}$. Fluorescence data files from each plate were analyzed using automated allele-calling software (SDS 2.1; Life Technologies). The lowest genotyping success rate was obtained for the rs5333 polymorphism ( $95 \%$ ) among controls and for the rs5333 and rs4639051 polymorphisms (95\%) among cases.

EDNRA gene polymorphisms were selected from the International HapMap Project [19]. Due to linkage disequilibrium between some of the 58 common polymorphisms, at least five polymorphisms had to be genotyped to estimate all haplotypes with more than $5 \%$ frequency and that would cover more than $90 \%$ of all possible EDNRA gene polymorphisms haplotypes. The EDN1 rs 1800541 and rs57072783 polymorphisms were selected on the basis of a previous study [20], which reported that these two polymorphisms are in almost complete linkage disequilibrium with other polymorphisms in this gene, thus covering more than $90 \%$ of gene variability.

\section{Statistical analysis}

Allele frequencies were determined by gene counting. The Chi square test was used to verify the Hardy-Weinberg equilibrium (HWE) and compare genotype and allele frequencies. Genotypes were evaluated assuming different genetic models, including additive, recessive and dominant. We examined widely used measures of linkage disequilibrium (LD), Lewontin's $\mathrm{D}^{\prime}\left|\mathrm{D}^{\prime}\right|$ and $r^{2}$ [21], between all pairs of biallelic loci in the EDNRA or $E D N 1$ genes. Phase 2.1 program was used to infer the haplotypes derived from the combination of the EDNRA and EDN1 gene polymorphisms [21]. This method is based in a Bayesian statistical method [21]. Phase 2.1 was also used to compare the distributions of different $E D N R A$ and EDN1 gene haplotypes between cases and controls through permutation analyses of 1000 random replicates [22].

The clinical and laboratory comparisons between groups were performed by the unpaired Student's test or the Chi square test as appropriate. Continuous variables were expressed as means and standard deviations (SD). Variables with a skewed distribution (serum creatinine, albuminuria, triglycerides, and ET-1) were logarithmically transformed and were presented as median (interquartile range). Odds ratio (OR) was used to assess the magnitude of the association between different genotypes and DKD with $95 \%$ confidence intervals $(95 \% \mathrm{CI})$. Bonferroni's test was used to correct for multiple comparisons. Multivariate logistic regression analyses were carried out to control for possible confounding factors and to assess the independence of associations between genotypes and DKD. A two-tailed $\mathrm{P}$ value of $<0.05$ was considered statistically significant. All statistical analyses were performed in the SPSS-Windows 16.0 environment.

\section{Results}

Sample profile

Table 1 presents the main clinical features of patients according to renal status. Cases were more often males and had a longer duration of T2DM than controls. Cases also had lower HDL cholesterol levels and higher triglycerides and blood pressure values as compared with controls. By definition, serum creatinine was higher among cases as compared with controls. These differences held after Bonferroni's correction for multiple comparisons.

\section{Genotype and allele distributions}

The distributions of the EDN1 and EDNRA gene polymorphisms in T2DM patients with and without DKD are shown in Table 2. All genotypes were in HardyWeinberg equilibrium ( $\mathrm{P}>0.05$; data not shown). The EDN1 rs1800541 polymorphism is in moderate LD with the EDN1 rs57072783 polymorphism $\left(\left|\mathrm{D}^{\prime}\right|=0.823\right.$ and $\left.r^{2}=0.788\right)$. LD coefficients $\left(\left|\mathrm{D}^{\prime}\right|\right.$ and $\left.r^{2}\right)$ between all biallelic combinations of the five EDNRA gene polymorphisms are presented in Table 3 . The analyzed EDNRA

Table 1 Clinical and laboratory profile of patients with type 2 diabetes mellitus according to renal status

\begin{tabular}{|c|c|c|c|}
\hline & $\begin{array}{l}\text { Controls } \\
(n=308)\end{array}$ & $\begin{array}{l}\text { Cases } \\
(n=240)\end{array}$ & $P^{*}$ \\
\hline Male gender, n (\%) & $118(38.3)$ & $144(60.0)$ & $<0.001$ \\
\hline $\begin{array}{l}\text { Duration of diabetes } \\
\text { (years) }\end{array}$ & $13.4 \pm 7.2$ & $17.2 \pm 9.6$ & $<0.001$ \\
\hline Age (years) & $60.6 \pm 9.7$ & $61.2 \pm 9.9$ & 0.477 \\
\hline $\mathrm{BMI}\left(\mathrm{kg} / \mathrm{m}^{2}\right)$ & $28.4 \pm 4.7$ & $28.4 \pm 5.2$ & 0.999 \\
\hline $\begin{array}{l}\text { Systolic blood pressure } \\
(\mathrm{mmHg})\end{array}$ & $142 \pm 23.5$ & $149 \pm 24.1$ & $<0.001$ \\
\hline $\begin{array}{l}\text { Diastolic blood pressure } \\
(\mathrm{mmHg})\end{array}$ & $85 \pm 13.5$ & $86 \pm 14.0$ & 0.398 \\
\hline HbA1c (\%) & $6.88 \pm 1.57$ & $6.85 \pm 2.06$ & 0.847 \\
\hline $\begin{array}{l}\text { Fasting plasma glucose } \\
\text { (mg/dL) }\end{array}$ & $161.8 \pm 59.5$ & $168.3 \pm 75.3$ & 0.260 \\
\hline $\begin{array}{l}\text { Serum creatinine } \\
(\mathrm{mg} / \mathrm{dL})\end{array}$ & $0.9(0.5-1.4)$ & $2.9(0.6-13.9)$ & $<0.001$ \\
\hline $\begin{array}{l}\text { Cholesterol, total } \\
(\mathrm{mg} / \mathrm{dL})\end{array}$ & $206 \pm 44.2$ & $203.1 \pm 52.6$ & 0.469 \\
\hline $\begin{array}{l}\text { Cholesterol, HDL } \\
\text { (mg/dL) }\end{array}$ & $46.7 \pm 11.5$ & $41.7 \pm 11.7$ & $<0.001$ \\
\hline Triglycerides (mg/dL) & $143(40-659)$ & $171(45-1265)$ & $<0.001$ \\
\hline
\end{tabular}

Data expressed as mean $\pm S D$, median (range) or $\%$

* P values computed by Chi square or Student's $t$ test as appropriate. Bonferroni threshold for multiple comparisons $=0.0042$ 
Table 2 Genotypic and allelic frequencies of EDN1 and EDNRA polymorphisms in white type 2 diabetic patients according to renal status

\begin{tabular}{|c|c|c|c|c|c|c|c|c|}
\hline & \multicolumn{2}{|c|}{ Genotype frequencies } & \multirow[t]{2}{*}{$\mathrm{P}^{*}$} & \multirow[t]{2}{*}{ OR (95 \% Cl) } & & \multicolumn{2}{|c|}{ Allele frequencies } & \multirow[t]{2}{*}{$\mathrm{P}^{* *}$} \\
\hline & Controls & Cases & & & & Controls & Cases & \\
\hline \multicolumn{9}{|l|}{ EDN1 } \\
\hline rs1800541 & $n=304$ & $n=239$ & & & & & & \\
\hline $\mathrm{TT}$ & $200(65.8)$ & $182(76.2)$ & 0.031 & 1 & $\mathrm{~T}$ & 0.806 & 0.866 & 0.011 \\
\hline GT & $90(29.6)$ & $50(20.9)$ & & $0.61(0.41-0.91)$ & G & 0.194 & 0.134 & \\
\hline GG & $14(4.6)$ & $7(2.9)$ & & $0.55(0.22-1.39)$ & & & & \\
\hline rs57072783 & $n=289$ & $n=224$ & & & & & & \\
\hline GG & $169(58.5)$ & $150(67.0)$ & 0.050 & 1 & $\mathrm{~T}$ & 0.234 & 0.183 & 0.062 \\
\hline TG & $105(36.3)$ & $66(29.5)$ & & $0.71(0.49-1.03)$ & G & 0.766 & 0.817 & \\
\hline $\mathrm{TT}$ & $15(5.2)$ & $8(3.6)$ & & $0.60(0.25-1.46)$ & & & & \\
\hline \multicolumn{9}{|l|}{ EDNRA } \\
\hline rs4835083 & $n=300$ & $n=233$ & & & & & & \\
\hline AA & $115(38.3)$ & $100(42.9)$ & 0.513 & 1 & A & 0.622 & 0.644 & 0.498 \\
\hline$A G$ & $143(47.7)$ & $100(43.9)$ & & $0.80(0.56-1.16)$ & G & 0.378 & 0.356 & \\
\hline GG & $42(14.0)$ & $33(14.2)$ & & $0.90(0.53-1.53)$ & & & & \\
\hline rs1568136 & $n=308$ & $n=240$ & & & & & & \\
\hline $\mathrm{TT}$ & $149(47.7)$ & $111(46.2)$ & 0.852 & 1 & A & 0.307 & 0.323 & 0.254 \\
\hline AT & $129(42.1)$ & $103(42.9)$ & & $1.07(0.75-1.53)$ & $\mathrm{T}$ & 0.693 & 0.677 & \\
\hline AA & $30(10.1)$ & $26(10.8)$ & & $1.16(0.65-2.08)$ & & & & \\
\hline rs4639051 & $n=287$ & $n=230$ & & & & & & \\
\hline AA & $183(63.4)$ & $157(68.3)$ & 0.040 & 1 & A & 0.814 & 0.826 & 0.113 \\
\hline$A G$ & $103(35.9)$ & $66(28.7)$ & & $0.75(0.51-1.09)$ & G & 0.186 & 0.174 & \\
\hline GG & $2(0.7)$ & $7(3.0)$ & & $4.08(0.84-19.29)$ & & & & \\
\hline rs5333 & $n=284$ & $n=230$ & & & & & & \\
\hline $\mathrm{TT}$ & $137(48.2)$ & $125(54.3)$ & 0.373 & 1 & $\mathrm{~T}$ & 0.695 & 0.728 & 0.282 \\
\hline TC & $121(42.6)$ & $85(37.0)$ & & $0.77(0.53-1.11)$ & C & 0.305 & 0.272 & \\
\hline $\mathrm{CC}$ & $26(9.2)$ & $20(8.7)$ & & $0.84(0.45-1.59)$ & & & & \\
\hline rs5343 & $n=299$ & $n=235$ & & & & & & \\
\hline $\mathrm{CC}$ & $120(40.1)$ & $105(43.8)$ & 0.470 & 1 & C & 0.698 & 0.645 & 0.113 \\
\hline $\mathrm{CT}$ & $38(46.2)$ & 97 (40.9) & & $2.92(1.85-4.61)$ & $\mathrm{T}$ & 0.302 & 0.355 & \\
\hline $\mathrm{TT}$ & 41 (13.7) & $36(15.3)$ & & $1.00(0.60-1.69)$ & & & & \\
\hline
\end{tabular}

Genotype frequencies expressed as $n(\%)$ and allele frequencies shown as proportions

Bonferroni threshold for multiple comparisons $=0.0071$

OR $(95 \% \mathrm{Cl}$ ) odds ratio (95\% confidence interval)

* P values computed by Chi square test for genotypes comparisons

** P values computed by Chi square test for allele frequencies comparisons

Table 3 Linkage disequilibrium (| $D^{\prime} \mid$ and $\left.r^{2}\right)$ between all biallelic loci of the EDNRA gene

\begin{tabular}{|c|c|c|c|c|c|c|}
\hline & $\left|D^{\prime}\right|$ & & & & & \\
\hline \multirow[t]{6}{*}{$r^{2}$} & & rs4835083 & rs1568136 & rs4639051 & rs5333 & rs5343 \\
\hline & rs4835083 & - & 0.576 & 0.133 & 0.359 & 0.452 \\
\hline & rs1568136 & 0.260 & - & 0.452 & 0.665 & 0.579 \\
\hline & rs4639051 & 0.007 & 0.099 & - & 0.802 & 0.635 \\
\hline & rs5333 & 0.090 & 0.394 & 0.349 & - & 0.657 \\
\hline & rs5343 & 0.182 & 0.087 & 0.051 & 0.100 & - \\
\hline
\end{tabular}


gene polymorphisms are not in significant LD with each other.

Cases had a lower frequency of the EDN1 rs1800541 G/G and G/T genotypes compared to controls $(P=0.031)$. Assuming a dominant model of inheritance (GG/GT vs. TT), presence of the $\mathrm{G}$ allele was associated with an OR of 0.60 (95 \% CI 0.41-0.88, $\mathrm{P}=0.009$ ). $\mathrm{G}$ allele frequency was 0.194 in controls versus 0.134 in cases $(P=0.01)$. Similar results were obtained when controls with more than 10 years of T2DM were analyzed (data not shown). Being conservative, both genotype and allele frequencies of rs1800514 polymorphism were not statistically different between case and control subjects after Bonferroni's correction (Table 2). However, on multivariate analysis, presence of the rs1800541 G allele remained independently associated with lower frequency of DKD after controlling for gender, T2DM duration, systolic BP, HbA1c and HDL cholesterol (OR $=0.67$, $95 \%$ CI 0.42-0.89; $\mathrm{P}=0.046)$. It bears noting that the prevalence of DKD was not different when assuming a recessive model of inheritance for the $G$ allele (GG vs. GT/TT; data not shown).

The EDN1 rs57072783 T/T and T/G genotypes exhibited a borderline association with DKD $(\mathrm{P}=0.05)$. Assuming a dominant model of inheritance, presence of the T allele (TT/TG vs. GG) was associated with an OR of 0.69 (95\% CI 0.48-0.99, P = 0.049), but this significance was not significant after multiple logistic regression analysis adjusting for gender, T2DM duration, systolic BP, HbA1c and HDL cholesterol $(P=0.196)$. The prevalence of DKD was not significantly different when assuming a recessive model of inheritance for the $T$ allele (TT vs. TG/GG; data not shown).

Genotype and allele frequencies of the EDNRA rs4835083, rs1568136, rs5333 and rs5343 polymorphisms were similar among cases and controls (all $\mathrm{P}$ values $>0.10$ ). The genotype distribution of the EDNRA rs4639051 polymorphism was significantly different between cases and controls $(P=0.04)$, but this association was lost after Bonferroni's correction.

The frequency of the heterozygous genotype was slightly lower and that of the major genotype (A/A) slightly higher among cases. However, given that the $G$ allele is rare, the genotype distribution pattern of this polymorphism could not be characterized as additive, dominant or recessive. The allele frequencies of the rs4639051 polymorphism were not different between cases and controls $(\mathrm{P}=0.113)$. On multivariate analysis, no association was observed between the rs4639051 polymorphism and DKD after controlling for gender, systolic BP, T2DM duration, HbA1c and HDL cholesterol $(\mathrm{P}=0.057)$.

\section{Haplotype distributions}

A Bayesian statistical method was used to estimate the frequencies of different haplotypes produced by the combination of the EDN1 or EDNRA gene polymorphisms. All four expected haplotypes constructed by the combination of the two EDN1 polymorphisms were observed (Table 4). The five polymorphisms of the EDNRA gene result in 24 different haplotypes, but only those with a frequency of $>5 \%$ are presented in Table 4 . For both genes, permutation analyses showed that haplotype distributions were not statistically different between case and control subjects.

\section{ET-1 levels}

ET-1 was measured in 111 patients who were able to discontinue medications that could interfere with ET-1 levels and did not have any acute or chronic conditions that could be associated with increased levels of ET-1. No differences in ET-1 levels were found among any of the polymorphisms analyzed (data not shown).

\section{Discussion}

A previous study reported that patients with T2DM had elevated ET-1 levels as compared with nondiabetic subjects [11]. Furthermore, plasma ET-1 levels are higher in macroalbuminuric than normoalbuminuric patients [14]. ET-1 is the most powerful endogenous vasoconstrictor, and has profibrotic and proinflammatory effects

Table 4 EDN1 and EDNRA haplotype frequencies in patients with type 2 diabetes mellitus according to renal status

\begin{tabular}{llll}
\hline Haplotype frequencies & Controls & Cases & $\mathbf{P}^{*}$ \\
\hline EDN1 & $\mathrm{n}=311$ & $\mathrm{n}=188$ & \\
$\mathrm{~T} / \mathrm{G}$ & 0.752 & 0.749 & 0.424 \\
$\mathrm{~T} / \mathrm{T}$ & 0.059 & 0.058 & \\
$\mathrm{G} / \mathrm{G}$ & 0.053 & 0.044 & \\
$\mathrm{G} / \mathrm{T}$ & 0.136 & 0.149 & \\
EDNRA & $\mathrm{n}=242$ & $\mathrm{n}=276$ & 0.278 \\
$\mathrm{G} / \mathrm{A} / \mathrm{A} / \mathrm{C} / \mathrm{C}$ & 0.089 & 0.072 & \\
$\mathrm{G} / \mathrm{A} / \mathrm{G} / \mathrm{C} / \mathrm{C}$ & 0.057 & 0.050 & \\
$\mathrm{G} / \mathrm{T} / \mathrm{A} / \mathrm{T} / \mathrm{T}$ & 0.100 & 0.090 & \\
A/T/A/T/C & 0.273 & 0.286 & \\
A/T/A/T/T & 0.178 & 0.180 & \\
\hline
\end{tabular}

The first letter of the END1 haplotype refers to the rs1800541 polymorphism and the second to the rs57072783 polymorphism. The first letter of the EDNRA haplotype refers to the rs 4835083 polymorphism, the second to the rs 1568136 , the third to the rs 4639051 , the fourth to the 5333 and the last to the rs5343 polymorphism

$n$ number of chromosomes

* P values for comparison of haplotype frequencies between patients with or without diabetic kidney disease were calculated using permutation tests (1000 replications) 
[23]. It has been found to affect three different aspects of renal physiology: vascular and mesangial tone; sodium and water excretion; and cell proliferation and matrix formation [13, 24]. Immunohistochemical studies of kidney biopsies of subjects with DKD show overexpression of ET-1 and ETRA [15]. In experimental rat models, endothelin antagonist treatment has a nephroprotective effect, correcting both the initial hyperfiltration and its progression to clinical DKD $[9,10]$ and reducing inflammation and podocyte injury [25]. The therapeutic potential of endothelin receptor antagonists in human kidney diseases featuring chronic proteinuria (including DKD) was recently reviewed [26]. A recent double-blind, placebo-controlled trial showed that the endothelin antagonist avosentan significantly reduced albuminuria when added to standard treatment in T2DM patients [27]. These studies provide further evidence of the role of ET-1 in the pathogenesis of DKD and of its status as a promising treatment target for this complication.

In the present study, two variants in the EDN1 gene were associated with DKD protection in white patients with T2DM. Presence of the EDN1 rs1800541 G allele and rs57072783 $\mathrm{T}$ allele was associated with a decreased risk of DKD. The association was stronger for the rs1800541 polymorphism and more evident when assuming a dominant model of inheritance. However, none of the polymorphisms were associated with plasma ET-1 levels.

A previous study investigating potential associations between a set of 45 polymorphisms located in 20 candidate genes and DKD in T2DM patients from the Czech Republic also reported a relationship between an EDN1 gene polymorphism (8002 G/A) and this diabetic complication using multi-locus analysis $(\mathrm{P}=0.033)$ [28]. However, this association did not remain statistically significant after adjusting for diabetes duration, HbA1c, diastolic BP and the presence of other DKD-associated polymorphisms located in three different genes, namely AGER-429T/C and 2184A/G, LTA 252A/G, and NOS3 $774 \mathrm{C} / \mathrm{T}$ and E298D. In T2DM obese subjects, the EDN1 $8002 \mathrm{~T}$ polymorphism was associated with a higher prevalence of combined microangiopathy (neuropathy/retinopathy/nephropathy) $(\mathrm{P}=0.035)$ [29].

A number of previous studies have linked EDN1 rs1800541 and rs57072783 polymorphisms with hypertension in individuals with overweight and obesity [30-32], as well as with HDL cholesterol metabolism [33]. These are known predisposing factors for the development of DKD. The relationship between these two polymorphisms and impaired renal function in a nondiabetic population was studied in the PREVEND Study cohort [20]. Haplotype analysis revealed that individuals carrying both the EDN1 rs1800541 G allele and EDN1 rs57072783 T allele showed decreased glomerular filtration and lower creatinine clearance than carriers of other haplotypes. No significant difference in ET-1 plasma levels was observed between haplotype groups. However, in this study, only normoalbuminuric and microalbuminuric patients were analyzed, whereas patients with overt proteinuria were excluded.

Recently, the rs57072783 $\mathrm{T}$ allele was associated with delayed onset of T2DM and reduced risk of diabetic retinopathy in a Chinese sample [34]. However, the rs57072783 T/T genotype was associated with elevated plasma ET-1 levels in pregnant women, and the $\mathrm{T}$ allele has been associated with raised systolic BP [35]. In our study, the protective association observed between presence of the rs57072783 T allele (TT or TG, dominant inheritance model) and DKD was statistically weak and did not remain independently associated with DKD after adjusting for gender, diabetes duration, systolic BP, HbA1c and HDL cholesterol.

Activation of ETRA in renal cells leads to a complex signaling cascade resulting in stimulation of mesangial cell proliferation, contraction, hypertrophy and extracellular matrix accumulation [4]. These renal alterations are associated with the onset and progress of DKD. Besides, ETRA is overexpressed in kidney of subjects with DKD [15]. SNP rs4639051 was the more promising polymorphism evaluate in EDNRA gene $(\mathrm{P}=0.04)$. However, likewise rs57072783, the association did not remain after controlling for possible confounding factors in multivariate analysis. Since BP could be involved in the pathway of endothelin system leading to DKD, we performed the multivariate analysis excluding this parameter. In both cases, the main result did not change (data not shown). The fact that we were not able to show an association of rs57072783 and rs4639051 with DKD, does not exclude their potential role. This might be evaluated in a larger sample of subjects.

A lower ET-1 level would be expected with the protective genotypes of EDN1 gene polymorphisms (rs1800541 and rs57072783). However, no difference was found in the present study. Since many situations could interfere with ET-1 levels, ET-1 could be measured in only 111 selected subjects. Those in whom the genetic effect was likely to be more marked were excluded a priori. This would be the case for those with advanced renal disease.

On the other hand, Tanaka et al. [36] investigated expression of the rs57072783 polymorphism in ET-1 in vitro: rs57072783 T allele cells were transfected and compared with $G$ allele transfected cells with preproET-1 in three different cell lines. The authors measured the levels of ET-1 and its precursor, big ET-1, in the culture supernatant and did not find a significant difference in levels of either substance between the 
T-type and G-type transfectant cells, suggesting that this polymorphism does not, in fact, play a significant role in ET-1 levels. Even though some minor effect on the processing of preproET-1 to mature ET-1 cannot be totally ruled out, it is more possible that rs57072783 is not the causal polymorphism, but only occurs in LD with an unknown functional polymorphism in the EDN1 gene. The rs57072783 polymorphism leads to an amino acid change in ET-1 precursor, but not in mature ET-1. Therefore, it is also possible that this polymorphism might affect the protein structure, modulating its binding affinity, without any changes in ET-1 levels. To the best of our knowledge, no other study has evaluated ET-1 levels according to different genotypes of the rs1800541 polymorphism.

We also used a Bayesian statistical method to estimate the frequencies of different haplotypes constructed by combination of the EDN1 or EDNRA gene polymorphisms. However, these haplotype analyses did not add any further information to the single polymorphism analyses, i.e. the frequencies of all observed EDN1 and $E D N R A$ gene haplotypes were not statistically different between case and control subjects. The selection of polymorphisms evaluated in our study sought to cover the most common haplotypes, and was based on a previous publication [20] and on HapMap Project data. Unfortunately, we cannot exclude the possibility that less frequent EDN1 or EDNRA gene haplotypes could have some effect on development of DKD.

The limitations of this study include its cross-sectional design, which can only lead to conclusions about associations, not causality. Still on the topic of the crosssectional design, 116 patients were on dialysis; therefore, we could expect changes in glycemic control, weight and HbA1c in this subset. This could explain our failure to find or decreasing the magnitude of differences in traditional risk factors between cases and controls. Therefore, we decided a priori which variables would be included in multivariate analysis rather than only using those with statistical significance on univariate analyses. Interestingly to note, the group of cases had more males, had longer diabetes duration, higher systolic BP and worst lipid profile. However, presence of the rs1800541 G allele remained associated with DKD after controlling for these possible confounding factors. Therefore, we believe these differences did not affect the main findings. Other factors could have interfered with our findings; for instance, the possibility of stratification bias cannot be discarded. Nevertheless, we only analyzed subjects who self-reported ethnicity as white, thus reducing the risk of false-positive or false-negative associations due to this bias. Therefore, the findings of the present study must be taken carefully taking into account that the reported associations did not held after Bonferroni's correction.

In conclusion, the present study demonstrated an independent association between a genetic variant in the EDN1 gene and DKD in white patients with T2DM. The effect appears minor, but is supported by the existing hypothesis that the ET-1 system would be involved in the development of DKD. Larger confirmatory studies in other populations are required to define the role of these polymorphisms in DKD.

\section{Abbreviations}

DKD: diabetic kidney disease; ESRD: end stage renal disease; ET-1: endothelin-1; ETRA: receptors type $A$; ETRB: receptors type $B$; EDN1: genetic variants of the ET-1 genes; EDNRA: genetic variants of the ETRA genes; T2DM: type 2 diabetes mellitus; BP: blood pressure; AER: albumin excretion rate; ACE: angiotensin-converting enzyme; PCR: polymerase Chain Reaction; HWE: Hardy-Weinberg equilibrium; LD: linkage disequilibrium; OR: odds ratio.

\section{Authors' contributions}

CMZ, DC, DAS, JLG, FG, LHC review the data, wrote and reviewed the manuscript. CMZ, DC, DAS, LPK collect the data and performed the laboratory analyzes. CMZ, JLG, DC and LHC designed the study, data collection and analysis, decision to publish, or preparation of the manuscript. All authors read and approved the final manuscript.

\section{Author details}

${ }^{1}$ Federal University of Rio Grande do Sul, Porto Alegre, Brazil. ${ }^{2}$ Endocrine Division, Hospital de Clínicas de Porto Alegre, Federal University of Rio Grande do Sul, Porto Alegre, RS, Brazil.

\section{Acknowledgements}

The study was supported by funds from the Conselho Nacional de Desenvolvimento Científico e Tecnológico (CNPq), Fundação de Amparo à Pesquisa do Estado do Rio Grande do Sul (FAPERGS) and Fundo de Incentivo à Pesquisa e Eventos (FIPE) at the Hospital de Clínicas de Porto Alegre.

\section{Grant support}

Conselho Nacional de Desenvolvimento Científico e Tecnológico (CNPq) e Fundo de Incentivo à Pesquisa (FIPE) from Hospital de Clínicas de Porto Alegre.

\section{Competing interests}

The authors declare that they have no competing interests.

Received: 8 April 2015 Accepted: 2 November 2015

Published online: 19 November 2015

\section{References}

1. 2014 National Chronic Kidney Disease Fact Sheet. http://www.cdc.gov/ diabetes/pubs/factsheets/kidney.htm\#1.

2. Valmadrid CT, Klein R, Moss SE, Klein BE. The risk of cardiovascular disease mortality associated with microalbuminuria and gross proteinuria in persons with older-onset diabetes mellitus. Arch Intern Med. 2000;160:1093-100.

3. Craig KJ, Donovan K, Munnery M, Owens DR, Williams JD, Phillips AO. Identification and management of diabetic nephropathy in the diabetes clinic. Diabetes Care. 2003;26:1806-11.

4. Barton M, Luscher TF. Endothelin antagonists for hypertension and renal disease. Curr Opin Nephrol Hypertens. 1999;8:549-56.

5. Levey AS, Coresh J, Balk E, Kausz AT, Levin A, Steffes MW, et al. National Kidney Foundation practice guidelines for chronic kidney disease: evaluation, classification, and stratification. Ann Intern Med. 2003;139:137-47. 
6. Ohta K, Hirata Y, Shichiri M, Kanno K, Emori T, Tomita K, et al. Urinary excretion of endothelin-1 in normal subjects and patients with renal disease. Kidney Int. 1991;39:307-11.

7. Benigni A, Perico N, Remuzzi G. Research on renal endothelin in proteinuric nephropathies dictates novel strategies to prevent progression. Curr Opin Nephrol Hypertens. 1001;10:1-6.

8. Hocher B, Schwarz A, Reinbacher D, Jacobi J, Lun A, Priem F, et al. Effects of endothelin receptor antagonists on the progression of diabetic nephropathy. Nephron. 2001;87:161-9.

9. Sorokin A, Kohan DE. Physiology and pathology of endothelin-1 in renal mesangium. Am J Physiol Renal Physiol. 2003:285:F579-89.

10. Gomez-Garre D, Ruiz-Ortega M, Ortego M, Largo R, Lopez-Armada MJ, Plaza JJ, et al. Effects and interactions of endothelin-1 and angiotensin II on matrix protein expression and synthesis and mesangial cell growth Hypertension. 1996;27:885-92.

11. Seligman BG, Biolo A, Polanczyk CA, Gross JL, Clausell N. Increased plasma levels of endothelin 1 and von Willebrand factor in patients with type 2 diabetes and dyslipidemia. Diabetes Care. 2000;23:1395-400.

12. Schneider JG, Tilly N, Hierl T, Sommer U, Hamann A, Dugi K, et al. Elevated plasma endothelin-1 levels in diabetes mellitus. Am J Hypertens. 2002;15:967-72.

13. De Mattia G, Cassone-Faldetta M, Bellini C, Bravi MC, Laurenti O, Baldoncini $R$, et al. Role of plasma and urinary endothelin-1 in early diabetic and hypertensive nephropathy. Am J Hypertens. 1998;11:983-8.

14. Zanatta CM, Gerchman F, Burttet L, Nabinger G, Jacques-Silva MC, Canani $\mathrm{LH}$, et al. Endothelin-1 levels and albuminuria in patients with type 2 diabetes mellitus. Diabetes Res Clin Pract. 2008:80:299-304.

15. Zanatta CM, Veronese FV, Loreto MDS, Sortica DA, Carpio VN, Eldeweiss $\mathrm{Ml}$, et al. Endothelin-1 and endothelin a receptor immunoreactivity is increased in patients with diabetic nephropathy. Ren Fail. 2012;34(3):308-15.

16. Canani LH, Costa LA, Crispim D, Goncalves Dos Santos K, Roisenberg I, Lisboa HR, et al. The presence of allele D of angiotensin-converting enzyme polymorphism is associated with diabetic nephropathy in patients with less than 10 years duration of Type 2 diabetes. Diabet Med. 2005;22:1167-72.

17. ZelmanovitzT, Gross JL, Oliveira JR, Paggi A, Tatsch M, Azevedo MJ. The receiver operating characteristics curve in the evaluation of a random urine specimen as a screening test for diabetic nephropathy. Diabetes Care. 1997:20:516-9.

18. Miller L, Gray L, Beachey E, Kehoe M. Antigenic variation among group A streptococcal M proteins. Nucleotide sequence of the serotype $5 \mathrm{M}$ protein gene and its relationship with genes encoding types 6 and $24 M$ proteins. J Biol Chem. 1988:263:5668-73.

19. The International HapMap project. Nature. 2003;426:789-96.

20. Pinto-Sietsma SJ, Herrmann SM, Schmidt-Petersen K, Niu T, Hillege $H L$, Janssen WM, et al. Role of the endothelin-1 gene locus for renal impairment in the general nondiabetic population. J Am Soc Nephrol. 2003;14:2596-602.

21. Hedrick PW. Gametic disequilibrium measures: proceed with caution. Genetics. 1987:117:331-41.
22. Stephens M, Smith NJ, Donnelly P. A new statistical method for haplotype reconstruction from population data. Am J Hum Genet. 2001;68:978-89.

23. Hopfner RL, Gopalakrishnan V. Endothelin: emerging role in diabetic vascular complications. Diabetologia. 1999:42:1383-94.

24. Ding SS, Qiu C, Hess P, Xi JF, Zheng N, Clozel M. Chronic endothelin receptor blockade prevents both early hyperfiltration and late overt diabetic nephropathy in the rat. J Cardiovasc Pharmacol. 2003;42:48-54.

25. Saleh MA, Boesen El, Pollock JS, Savin VJ, Pllock DM. Endothelin receptor A-specific stimulation of glomerular inflammation and injury in a streptozocin-induced rat model of diabetes. Diabetologia. 2011;54:979-88.

26. Barton M. Therapeutic potential of endothelin receptor antagonists for chronic proteinuric renal disease in humans. Biochem Biophys Acta. 2010;1802:1203-13.

27. Mann JF, Green D, Jamerson K, et al. Avosentan for overt diabetic nephropathy. J Am Soc Nephrol. 2010;21:527-35.

28. Kankova K, Stejskalova A, Pacal L, Tschoplova S, Hertlova M, Krusova D, et al. Genetic risk factors for diabetic nephropathy on chromosomes $6 \mathrm{p}$ and $7 \mathrm{q}$ identified by the set-association approach. Diabetologia. 2007;50:990-9.

29. Manea SA, Robciuc A, Guja C, Heltianu C. Identification of gene variants in NOS3, ET-1 and RAS that confer risk and protection against microangiopathy in type 2 diabetic obese subjects. Biochem Biophys Res Commun. 2011;407(3):486-90.

30. Asai T, Ohkubo T, Katsuya T, Higaki J, Fu Y, Fukuda M, et al. Endothelin-1 gene variant associates with blood pressure in obese Japanese subjects: the Ohasama Study. Hypertension. 2001;38:1321-4

31. Jin JJ, Nakura J, Wu Z, Yamamoto M, Abe M, Tabara Y, et al. Association of endothelin-1 gene variant with hypertension. Hypertension. 2003:41:163-7.

32. Treiber FA, Barbeau P, Harshfield G, Kang HS, Pollock DM, Pollock JS, et al. Endothelin-1 gene Lys198Asn polymorphism and blood pressure reactivity. Hypertension. 2003;42:494-9.

33. Pare G, Serre D, Brisson D, Anand SS, Montpetit A, Tremblay G, et al. Genetic analysis of 103 candidate genes for coronary artery disease and associated phenotypes in a founder population reveals a new association between endothelin-1 and high-density lipoprotein cholesterol. Am J Hum Genet. 2007;80:673-82.

34. Li H, Louey JW, Choy KW, Liu DT, Chan WM, Chan YM, et al. Lys198Asn is associated with diabetic retinopathy in type 2 diabetes. Mol Vis. 1008;14:1698-704.

35. Barden AE, Herbison CE, Beilin LJ, Michael CA, Walters BN, Van Bockxmeer FM. Association between the endothelin-1 gene Lys198Asn polymorphism blood pressure and plasma endothelin-1 levels in normal and pre-eclamptic pregnancy. J Hypertens. 2001;19:1775-82.

36. Tanaka C, Kamide K, Takiuchi S, Kawano Y, Miyata T. Evaluation of the Lys198Asn and -134delA genetic polymorphisms of the endothelin-1 gene. Hypertens Res. 2004;27:367-71.

\section{Submit your next manuscript to BioMed Central and take full advantage of:}

- Convenient online submission

- Thorough peer review

- No space constraints or color figure charges

- Immediate publication on acceptance

- Inclusion in PubMed, CAS, Scopus and Google Scholar

- Research which is freely available for redistribution

Submit your manuscript at

www.biomedcentral.com/submit

C BioMed Central 